\title{
Peptides in Metabolic Autonomic Nerves
}

\author{
K. Uvnäs-Wallensten \\ Department of Pharmacology, Karolinska Institutet, Stockholm, Sweden
}

\begin{abstract}
Summary. Most polypeptides originally assigned to a specific organ and a specific effect seem to occur in many different parts of the body, in neurons as well as in endocrine cells. Thus gastrin and insulin, or very similar peptides can be demonstrated in extracts of the vagal nerves and of peripheral somatic nerves. Electrical stimulation of the sciatic nerve of a perfused cat leg causes appearance of gastrin and insulin like immunoreactivity in the perfusates. This gastrin and insulin like immunoreactivity might originate from nervous depots. If so it might be assumed that insulin and other peptides are released in response to activation of autonomic or somatic nerves and that they might exert local metabolic effects in response to the acute needs of energy in eg. striated or smooth muscles.
\end{abstract}

Key words: Peptidergic nerves, peptides, insulin, gastrin, release, local effects

Recently it has become obvious that peptides, previously assigned to specific functions in specific organs, are universally distributed in the body and most certainly involved in the regulation of many different physiological functions. Thus, the classical gastrointestinal hormones, gastrin and cholecystokinin, which are located in endocrine cells in the mucosa of the antrum and duodenum, also occur in neurons of the brain $[1,2]$. On the other hand somatostatin which was originally demonstrated by Brazeau et al [3] in the hypothalamus, has been found in endocrine cells in the mucosa of the entire gastrointestinal tract as well as in many other endocrine glands [4]. The same peptide may occur in endocrine-like cells as well as in classical neurons, and they might induce their effects by neurocrine, neuroparacrine, paracrine, endocrine and perhaps intraluminal actions.
The present article describes the presence of peptides in the peripheral nervous system with special references to the vagus nerve of the cat. The peripheral nervous system consists of the autonomic nervous system, including the parasympathetic and the sympathetic nerves, and the peripheral somatic nerves. All of these contain sensory as well as motor neurons. Until recently acetylcholine was considered to be the main transmitter substance in the preganglionic sympathetic and parasympathetic motor fibres, in the postganglionic parasympathetic motor fibres and also in the peripheral somatic motor nerves. Noradrenaline was supposed to be the transmitter of the sympathetic postganglionic motor fibres. Very little was known about the transmitter or transmitters of the sensory neurons in the peripheral nervous system.

The vagal nerve is the main regulator of gastrointestinal function. According to pharmacological terminology, vagally induced effects are mediated via cholinergic receptors of the muscarinic type and can therefore be blocked by atropine. However, exceptions to this rule were described before the era of peptides. For example, Martinsson [5] showed that the gastric relaxation which could be induced by electrical vagal stimulation using impulses of long duration $(\sim 2 \mathrm{msec})$ could not be blocked by atropine. Furthermore the endocrine responses following electrical vagal stimulation sometimes appeared to be mediated via a noncholinergic mechanism, since neither the gastrin $[6,7]$, nor the insulin [8] nor glucagon [9] release responses induced by such stimulation could be blocked by atropine.

\section{Peptides in the Vagus}

The atropine resistance of the vagally controlled release of gastrointestinal hormones might hypothetically be explained by a release of these peptides 
directly from vagal nerve terminals. Looking for such a "vagal pool" of gastrointestinal hormones, vagal extracts were assayed for various peptides. We were able to demonstrate the presence of gastrin [10] somatostatin [11] and insulin-like immunoreactivity (to be published) in extracts of the subdiaphragmatic vagus. The gastrin-like immunoreactivity corresponds to gastrin-17 and small amounts of gastrin-34 in cats, dogs and humans [10]. Large amounts of met and leu-enkephalin (ratio 4:1) are present in the vagus as determined by radioreceptorassay in combination with HPLC (Uvnäs-Wallensten and Stein, unpublished).

Lundberg et al. $[12,13,14]$ have made an extensive study of peptidergic fibres in the vagus using immunohistochemical methods. They have demonstrated the presence of substance $\mathrm{P}$, gastrin-CCK, VIP, enkephalin and somatostatin-like immunoreactivity after ligation of vagal nerves, suggesting that the peptides are transported in the nerves. They have also been able to show VIP, somatostatin, substance $\mathrm{P}$ and gastrin-CCK-like immunoreactivity in the cell bodies of the nodose ganglion, indicating that these peptides are present in sensory neurons. Most of the peptides are transported distally in the vagus irrespective of their presence in motor or sensory neurons.

The substance P-like immunoreactivity of the vagal nerve extracts has been further characterized by gel filtration. A peak corresponding to synthetic substance $P$ as well as a larger molecule was found. Dockray et al. [15] have shown that in most vagal extracts from dogs, CCK-8 seems to predominate over gastrin-17 [16], whereas some dog vagi contain only gastrin- 17 .

\section{Release of Peptide Following Vagal Stimulation}

Most of the peptides demonstrated in the vagus have been shown to be released in response to vagal activation. Gastrin [7, 18], insulin [8] and VIP (pig) [19] levels increase in portal blood following electrical vagal stimulation, whereas somatostatin levels decrease [20]. Gastrin [18], somatostatin [21], VIP [22] and substance $P$ [23] are released into the antral lumen of cats in response to such activation. However, since the vagal peptides occur in endocrine-like cells of the gastrointestinal tract and of the pancreas and also in neurons intrinsic to the gastrointestinal tract [17], it is of course difficult to assess to what extent the peptides released derive from the vagal nerves. We now think that the vagally induced gastrin release response derives only to a minor extent from the vagal nerves per se. Bombesin [24], which is a potent releaser of gastrin, is present in neurons intrinsic to the wall of the stomach and the intestine [25]. We have recently been able to demonstrate a release of bombesin into the portal vein of cats in response to electrical vagal stimulation (Uvnäs-Wallensten and Walsh to be published). It is therefore possible that bombesin is the transmitter in the postganglionic vagal neuron innervating the gastrin containing G-cells and perhaps also of other endocrine cells in the gastrointestinal tract. Extracts of cat pancreas also contain bombesin-like immunoreactivity (Walsh, Uvnäs-Wallensten and Lundberg, to be published), indicating that this peptide might have a similar function in the pancreas.

\section{Release of Peptides from Peripheral Somatic Nerves}

In order to study the release of neurogenic peptides, we shifted our interest to the peripheral somatic nerves. The general occurrence of peptides to all kinds of nervous tissue suggested to us that the sciatic nerve might also contain peptides. To test this hypothesis, an experimental model consisting of an extirpated cat leg was designed. During the experiments the vascular system of the cat leg is perfused with Tyrodes solution at a rate of $1 \mathrm{ml} / \mathrm{min}$ at room temperature. The perfusates are collected in icechilled tubes, boiled for $1 \mathrm{~min}$ and then frozen until assayed for peptides.

In response to electrical stimulation of the sciatic nerve, gastrin-like immunoreactivity appeared in the perfusate [26]. In experiments giving high yields, the nature of the gastrin-like immunoreactivity has been characterized as gastrin-17 by Dockray and Gregory (to be published). We have also been able to show a release of insulin [27] and somatostatin-like immunoreactivity (Uvnäs-Wallensten and Efendic, unpublished) in response to electrical stimulation of the sciatic nerve.

A release of these presumably neurogenic peptides can also be induced by adding drugs to the perfusion medium. Sulphonylureas (tolbutamide and glibenclamide) and $\mathrm{KCl}$ are potent releasers of both gastrin [28] and insulin-like material [29] from the sciatic nerve.

Both gastrin- and insulin-like immunoreactivity appear in perfusate from the Langendorff-heart preparation in response to electrical stimulation of the vagosympathetic trunk $[26,27]$ or following addition of $\mathrm{KCl}$ to the perfusion medium (to be published). Gersl et al. [30] have demonstrated that the concentration of gastrin (chromatographically identified as gastrin-17) is 10 to 100 fold higher in the heart atria than in the ventricles. The atria are richly vagally innervated but the ventricles are not. It therefore seems plausible that the gastrin extracted from the 
atria, at least to some extent, derives from vagal terminals.

\section{Peptides in Peripheral Somatic Nerves}

Lundberg et al. [13, 31] and Hökfelt et al. [32] have by means of immunocytochemistry demonstrated the presence of gastrin-CCK, somatostatin, substance $\mathrm{P}$, enkephalin and VIP-immunoreactive fibres in the sciatic nerve after ligation of the nerve. The peptide pattern is very similar to that of the vagal nerves and the distribution of peptides in sensory or motor fibres also agrees well. Gastrin-CCK, somatostatin, VIP and substance $\mathrm{P}$ can also be demonstrated in sensory spinal ganglia suggesting they are located in sensory neurons.

Interestingly insulin-like immunoreactivity has not been demonstrated immunocytochemically. We have recently been able to show that insulin-like material accumulates proximally following ligation of the sciatic nerve (Uvnäs-Wallensten and Uvnäs, to be published). The insulin-like material found in extracts of the vagus, the atria of the heart and in heart perfusates is indistinguishable from pancreatic insulin in several chromatographic systems (Uvnäs and Uvnäs-Wallensten, to be published). We therefore feel confident that the insulin-like material we study corresponds to insulin or a very similar peptide.

\section{Function of Peptides in Neurons}

As yet, not much is known about the physiological functions of the peptidergic neurons in the vagi. VIPergic neurons have been suggested to mediate the vagally induced gastric relaxation and also some reflexly induced vasodilator responses in the intestine [33]. The gastrointestinal sphincters are richly innervated by VIPergic [34] and enkephalin-containing fibres [35]. It has recently been proposed that VIP and enkephalin might mediate the vagally-controlled relaxation and contraction of the pylorus respectively [36].

Substance $\mathrm{P}$ is a potent vasodilator and has been suggested to be involved in the axon reflex inducing antidromic vasodilation [37]. Since substance $P$ is released into the antral lumen in response to vagal stimulation [23] it might be assumed to have similar vasodilator actions in the gastrointestinal tract. Bombesin might, as mentioned above, be involved in the vagally-induced release of gastrointestinal (and perhaps pancreatic) hormones. Somatostatin inhibits secretory and motor functions in the gastrointestinal tract [38]. It is possible that selective activation of vagal somatostatin fibres may be one of the ways by which the CNS can control gastrointestinal functions, perhaps via modulation of cholinergic transmission [39]. The occurrence of gastrin in the heart and in peripheral neurons suggests that neurogenic gastrin might be involved in a function common to most parts of the body. It is well known that gastrin exerts a trophic influence on the mucosa of the corpus and intestine [40]. Furthermore, infusions of gastrin to pregnant dogs or puppies have been shown to cause hypertrophy of the pylorus [41]. Analogously, gastrin might have trophic effects on striated muscles as well. Such an effect might explain why the size of a muscle increases in response to increased physical activity. It is also possible that gastrin modulates cholinergic transmission by increasing the release of aetylcholine [42].

The last peptide to be discussed is insulin. To us it seems reasonable to assume that neurogenic insulin regulates metabolic processes in the same way as insulin carried in the blood does. However with a neural supply of insulin, the metabolic effects of insulin could be increased locally in a tissue where it is needed. Thus, insulin might be released in response to activation of the nerves (autonomic or somatic) innervating smooth or striated muscles, together with acetylcholine (and other peptides) to cope with the acute metabolic needs of the working muscle.

\section{References}

1. Vanderhaegen JJ, Signeau JC, Gepts W (1975) New peptide in the vertebrate CNS reacting with antigastrin antibodies. Nature 257: 604-605

2. Dockray GJ (1976) Immunochemical evidence of cholecystokinin like peptides in the brain. Nature 264: 568-570

3. Brazeau P, Vale W, Burgus R, Ling N, Butcher M, Rivier J, Guillemin R (1973) Hypothalamic polypeptide that inhibits the secretion of immunoreactive pituitary growth hormone. Science 179: 77-79

4. Hökfelt T, Efendic S, Hellerström C, Johansson O, Luft R, Arimura A (1975) Cellular localization of somatostatin in endocrine like cells and neurons of the rat with special reference to the A-cells of the pancreatic islets and to the hypothalamus. Acta Endocrinol [Suppl 200] (Kbh) 80

5. Martinsson J (1965) Vagal relaxation of the stomach. Experimental reinvestigation of the concept of the transmission mechanism. Acta Physiol Scand 64: 453-462

6. Smith CL, Kewenter J, Connell AM, Ardill J, Hayes R, Buchanan K (1975) Control factors in the release of gastrin by direct electrical stimulation of the vagus. Dig Dis 20: 13-22

7. Uvnäs-Wallensten K, Andersson H (1977) Effect of atropine and methiamide on vagally induced $\mathrm{HCl}$ secretion and gastrin release in anesthetized cats. Acta Physiol Scand 99: 496-502

8. Uvnäs-Wallensten K, Nilsson G (1978) A quantitative study of the insulin release induced by vagal stimulation in anesthetized cats. Acta Physiol Scand 102: 137-142

9. Uvnäs-Wallensten K (1976) Effect of atropine on vagally induced release of gastrin, insulin and glucagon in anesthetized cats. Abstracts V. Intern. Congr. of Endocrinol., Hamburg

10. Uvnäs-Wallensten K, Rehfeld JF, Larsson LJ, Uvnäs B (1977) Heptadecapeptide gastrin in the vagal nerve. Proc Natl Acad Sci USA 74: 5707-5710 
11. Uvnäs-Wallensten K, Efendic S, Luft R (1978) The occurrence of somatostatin in the vagal nerves. Acta Physiol Scand 102: $248-250$

12. Lundberg JM, Hökfelt T, Schulzberg M, Nilsson G, UvnäsWallensten K, Terenius L, Dahlström A, Rehfeld JF, Elde RP, Said S (1978) Pathways of peripheral peptide neurons with special reference to the vagus nerve. Second European Neurosciences Meeting, Florence. Neuroscience Lett [Suppl 224]

13. Lundberg JM, Hökfelt T, Änggård A, Uvnäs-Wallensten K, Bremijoin S, Brodin E, Fahrenkrug J (1980) Peripheral peptide neurons: Distribution, axonal transport and some aspects on possible function. In: Kosta $\mathrm{E}$, Trabucci $\mathrm{M}$ (eds) Regulation and function of neural peptides. Advances in biochemical psychopharmacology. Raven Press, New York

14. Lundberg JM, Hökfelt T, Kewenter J, Petterson G, Ahlman H, Eden R, Dahlström A, Nilsson G, Terenius L, Uvnäs-Wallensten K, Said S (1979) Substance P, VIP and enkephalin like immunoreactivity in the human vagus nerve. Gastroenterology 77: 468-471

15. Gamse R, Lembeck F, Cuello AC (1979) Substance P in the vagus nerve. Immunochemical and immunohistochemical evidence for axoplasmic transport. Naunyn Schmiederbergs Arch Pharmacol 306: 37-44

16. Dockray GJ, Gregory RA, Tracy H (1980) Cholecystokinin octapeptide in dog vagus nerve: identification and accumulation on the cranial side of ligatures. J Physiol (Lond) 301: 50

17. Schultzberg M, Dreyfus CF, Gershon MD, Hökfelt T, Elde RD, Nilsson G, Said S, Goldstein M (1978) VIP - enkephalin - substance $P$ and somatostatin-like immunoreactivity in neurons intrinsic to the intestine; immunohistochemical evidence from organotypic tissue cultures. Brain Res 155: 239-248

18. Uvnäs-Wallensten K (1977) The occurrence of gastrin in gastric juice, antral secretions and antral perfusates of anesthetized cats. Gastroenterology 73: 487-491

19. Fahrenkrug J, Galbo H, Holst IJ, Schaffalitzky de Muckadell OB (1978) Influence of the autonomic nervous system on the release of vasoactive intestinal polypeptide from the gastrointestinal tract. J Physiol (Lond) 280: 405-422

20. Uvnäs-Wallensten $K$, Efendic $S$, Roovete A, Johansson $C$ (1980) Decreased release of somatostatin in the portal vein following electrical vagal stimulation in the cat. Acta Physiol Scand 109: 393-398

21. Uvnäs-Wallensten K, Efendic S, Luft R (1977) Vagal release of somatostatin into the antral lumen of cats. Acta Physiol Scand 99: 126-128

22. Uvnäs-Wallensten K (1977) Vagal release of antral hormones In: Bloom SR (ed) Gut hormones. Churchill Livingston, Edinburgh, 389-393

23. Uvnäs-Wallensten K (1978) Release of substance $\mathbf{P}$ into the antral lumen of cats. Acta Physiol Scand 104: 464-468

24. Bertaccini G, Erspamer V, Melchiorri P, Sopranzi N (1974) Gastrin release by bombesin in the dog. Br J Pharmacol 52: 219-225

25. Dockray GJ, Vaillant C, Walsh JH (1979) The neuronal origin of bombesin-like immunoreactivity in the rat gastrointestinal tract. Neuroscience 4: 1561

26. Uvnäs-Wallensten K, Uvnäs B (1978) Release of gastrin on stimulation of the sciatic and brachial nerves of the cat. Acta Physiol Scand 103: 349--351

27. Uvnäs B, Uvnäs-Wallensten K (1978) Insulinergic nerves to the skeletal muscles of the cat? Acta Physiol Scand 103: $346-348$
28. Uvnäs-Wallensten K, Efendic S, Lundberg J, Uvnäs B (1979) Release of gastrin from skeletal muscles and from the antral mucosa in cats induced by sulfonuric drugs. Acta Physiol Scand 106: 267-270

29. Uvnäs-Wallensten K (1979) Release of gastrin and insulin by electrical vagal stimulation and sulfonuric drugs from endocrine cells and nerves in the cat. In: Rosselin G, Fromageot P, Bonfils $S$ (eds) Hormone receptors in digestion and nutrition. Elsevier/North Holland, Amsterdam, p 493-500

30. Gersl W, Goiny M, Uvnäs-Wallensten K, Uvnäs B (in press) The occurrence of Gastrin-17 in the heart. Acta Physiol Scand

31. Lundberg JM, Hökfelt T, Nilsson G (1978) Peptide neurons in the vagus, splanchnic and sciatic nerves. Acta Physiol Scand 104: 499-501

32. Hökfelt T, Elde R, Johansson O, Luft R, Nilsson G, Arimura A (1976) Immunohistochemical evidence for separate populations of somatostatin containing and substance $\mathbf{P}$ containing primary afferent neurons in the rat. Neuroscience 1: 131

33. Fahrenkrug J, Haglund U, Jodal M, Lundgren $\mathrm{O}$, Olbe L, Schaffalitzky de Muckadell OB (1978) Nervous release of vasoactive intestinal polypeptide in the gastrointestinal tract of cats: Possible functional implications. J Physiol (Lond) 284: 291-305

34. Edin R, Lundberg JM, Ahlman H, Dahlström A, Fahrenkrug J, Hökfelt T, Kewenter J (1979) On the VIP-ering innervation of the feline pylorus. Acta Physiol Scand 107: 185-187

35. Elde K, Hökfelt T, Johansson $O$, et al (1976) Immunohistochemical studies using antibodies to leucin enkephalin initial observations on the central nervous system of the rat. Neuroscience 1: 349-351

36. Edin R (1980) The vagal control of the pyloric motor function. A physiological and immunohistochemical study in cat and man. Acta Physiol Scand [Suppl] 485

37. Henry JL (1977) Substance $P$ and pain: a possible relation in afferent transmission. Raven Press, New York, p 231-240

38. Efendic S, Johansson C, Thulin L, Uvnäs-Wallensten, $\mathrm{K}$ (in press) Somatostatin in the gastrointestinal tract. Proceedings of the 10th congress of International Diabetes Federation in Vienna. Excerpta Medica, Amsterdam

39. Guillemin R (1976) Somatostatin inhibits the release of acetylcholine induced electrically in the myenteric plexus. Endocrinology 99: 1653-1654

40. Johnson LR (1974) Gut hormones on growth of gastrointestinal mucosa. In: Chey WY, Brooks FP (eds) Endocrinology of the Gut. Charles B Slack, Thorofare NJ, p 163-177

41. Dodge JA (1970) Production of duodenal ulcers and hypertrophic pyloric stenosis by administration of pentagastrin to pregnant and newborn dogs. Nature 222: 284-285

42. Vizi SM, Impicciatore G, Bertaccini G, Knoll J (1973) Evidence that acetylcholine released by gastrin and related polypeptides contributes to their effect on gastrointestinal motility. Gastroenterology 64: 268-277

K. Uvnäs-Wallensten

Department of Pharmacology

Karolinska Institutet

Fack

S-10401 Stockholm 60

Sweden 


\section{Discussion after Uvnäs-Wallensten's Presentation}

Steffens: I am interested in the physiological function of the insulin you have found in the somatic nerves. Do you feel that the insulin is a neurotransmitter in the limb?

Uvnäs-Wallensten: I think that the insulin released when we stimulate the nerves acts the same way as circulating insulin, but only very locally. When motor activity is increased, there is of course a release of acetylcholine which activates the nicotinic receptors. At the same time, there may be a small amount of insulin released to stimulate glucose uptake; and VIP may be released in small amounts to dilate the blood vessels in the immediate area. There may also be a little gastrin to exert a trophic effect. It would obviously be much more efficient for muscles to have needed peptides available locally for optimal functioning and not have to depend totally upon the pancreas or other tissues.

Porte: Have you looked for insulin in diabetic animals?

\section{Uvnäs-Wallensten: No.}

Porte: The reason I ask is that there is now evidence that insulin can be internalized by insulin sensitive tissues. Is it possible that the insulin you are measuring is insulin which circulated to the nerves, was internalized, and appears to be released when the muscle is active? It's well known that nerves are insulin sensitive, and Dr. van Houten has evidence that neurons in the brain can internalize insulin. Perhaps the nerves to the limb take up insulin centrally and it is transported along the axons to the muscles. This would mean that the internalized insulin does not go through the lysosomal pathway.

Uvnäs-Wallensten: All of what you say is possible, but it would have to occur for several peptides. Further, the gastrin which we have measured is gastrin-17, which occurs in very low concentrations in the circulation of cats.

Porte: Yes, but gastrin is known to exist in some neurons and their cell bodies. Insulin may be a different story because it is not easy to find immunoreactive insulin inside cell bodies. At least we can't find it.

Uvnäs-Wallensten: I agree, because we haven't been able to find it either; but there are other possibilities. There is a precedent for two or more transmitters occurring in the same neuron. Perhaps acetylcholine and insulin co-exist in motor neurons and that the acetylcholine somehow interferes with visualization of the insulin.

Bray: You seem to have just destroyed a long-standing concept I have had that one neuron releases only one transmitter type. Do your data really show that more than one transmitter is found and released from the same neuron, or is it possible in your experiments that you stimulate a number of small axons, each of which has its own, unique transmitter?

Uvnäs-Wallensten: My own data cannot differentiate these; but considerable data from Hökfelt's group now show the co-existence of norepinephrine and somatostatin, of VIP and acetylcholine, and of dopamine with gastrin or CCK.

Bray: And are these examples found in the same terminal of one axon?

\section{Uvnäs-Wallensten: Yes.}

Smith: It is also possible, as recently suggested by Polak and Buchan (J Histochem Cytochem (1980) 28: 618) that the presence of amines within the cell blocks or masks a portion of the peptide molecule such that antibodies do not react with the peptide. We were recently doing some work with motilin, and we had an antibody which picked up MLI (motilin-like immunoreactivity) in serotonin-containing enterochromaffin cells whereas other motilin antibodies would not. The histological method used may be very important when looking at neurons with more than one transmitter. For example, it has often been observed that the indirect fluorescence technique works well in a given situation where the peroxidase-antiperoxidase technique, which is supposedly one to ten thousand times more sensitive, does not work at all. Some antibodies have been shown to find somatostatin in nerve cell bodies but not in fibers, and others find exactly the opposite. So there are a number of technical problems for which we have no easy answer.

Goldman: Is it possible that the binding of a peptide differs in different parts of a neuron?

Smith: It's very probable.

Fernstrom: I think that it's a reasonable hypothesis that the same nerve terminal might contain more than one transmitter, but you must be cautious. There's a good example of a sympathetic postganglionic nerve to the pineal gland which secretes norepinephrine but which also contains considerable serotonin. The serotonin appears non-functional. The pineal makes so much of it that some leaks out and gets concentrated by these nerve endings. So the neuron has one actual transmitter, norepinephrine, and one false transmitter. So I think that the chemical demonstration of two transmitter candidates should be interpreted cautiously.

Uvnäs-Wallenstein: In the instance of VIP and acetylcholine, I think it has been shown very convincingly by Drs. Lundberg and Änggård that both are required as a part of the secretory product in the salivary gland. If you apply only acetylcholine to the gland, or only VIP, huge amounts are required to get a response and the secretion is not normal. When the two are combined, minute amounts are very effective. Likewise, acetylcholine and gastrin more efficiently stimulate gastric acid secretion together than either alone.

Fernstrom: What's the possibility that when you crush a nerve, as in your experiments, growth cones form and a number of metabolic changes occur in the nerves and Schwann cells such that a super-binding of insulin and perhaps other peptides occurs? If this occurs, the material 
you observe may not be coming down the axon but may be binding to the outside.

Uvnäs-Wallensten: Yes, we can't exclude that possibility; but Dr. L. Kaijser a colleague of mine in the Department of Clinical Physiology at Karolinska Hospital has put catheters into the deep veins of muscles in humans and found that as they do physical work, more insulin can be measured in the vein than in the artery; and this persists for up to 3 hours. So again the suggestion is that it is being made there and released, for when the work stops, the insulin levels in the veins go down again.

Porte: Have you looked for C-peptide in your isolated limb preparation?

Uvnäs-Wallensten: No, we use cats, and there is no assay for cat C-peptide.

Van-Houten: There's a paper by Eng and Yalow (Diabetes (1980) 29: 105) suggesting that the amount of insulin in brain could be explained by bound insulin. Is it possible that in your peripheral limb preparation, the nerve stimulation releases insulin bound to receptors on the blood vessels?

Uvnäs-Wallensten: It is, of course, possible, but we wash the vessels with an insulin-free solution for one hour before the experiments. By the time we stimulate the nerves, no blood at all can be found in the perfusate from the limb.

Van-Houten: Dr. Fernstrom mentioned the possibility that damaged tissue might contribute. We have noticed that when we damage neural tissue with an electrolytic lesion, the blood vessels around the lesion bind a lot more insulin than normal.

Havrankova: How do you stimulate the nerves? Do you use a stimulus which is close to being physiological?

Uvnäs-Wallensten: We use techniques developed for stimulating the smaller, non-myelinated fibres of the gas- trointestinal tract. When we use parameters optimal for stimulating the larger, myelinated fibres, we get no effect.

Goldman: Based on your ligation studies, you would infer that if the nerve were cut, one could collect insulin from the cut end and that stimulating the proximal side should increase the rate of release of the insulin. Have you tried this?

Uvnäs-Wallensten: Not yet.

F. Jeanrenaud: Are all these peptides found in sympathetic nerves as well as parasympathetic and somatic nerves?

Uvnäs-Wallensten: Yes, all but insulin has been demonstrated in the cat, including neurotensin. We haven't looked for insulin in sympathetic neurons yet.

Goldman: Have you looked at other species?

Uvnäs-Wallensten: Cats are best in our experiments because they seem to have ten times more peptides than other species; but dogs and humans have been studied and have the same peptides, including insulin.

Berthoud: What about the rat?

Uvnäs-Wallensten: We haven't looked. Rats are too small for our experiments.

Samols: In quantitative terms, can you differentiate the amount of a peptide coming out of a nerve from that coming out of the antrum? This would be useful since the antral secretion of some peptides varies with the $\mathrm{pH}$ of the lumen.

Uvnäs-Wallensten: The problem is that $99 \%$ of what we would measure in that experiment would normally be from the antrum, so we could never tell what actually came from the nerve.

Oomura: There is evidence in the brain that LHRH may also be a neurotransmitter. Have you looked for it in your peripheral nerve preparation?

Uvnäs-Wallensten: That's a new one. I don't think anybody has looked for it. 